\title{
Vorbemerkung zum Roman „Eine Proletarierin“
}

In diesem Roman ist viel Autobiographisches des Ehepaars Struve enthalten; zugleich seine Ideen und Phantasien von sich selbst und ihren Idealen.

Max von Löwenstein kündigt seine Beamtenstelle und legt seinen Adelstitel ab wie Gustav Struve, der 1831 seine „aussichtsreiche Beamtenstelle“ gekündigt und 1847 seinen Adelstitel abgelegt hatte. Löwenstein ist wie Gustav Struve Gefangener in Rastatt und Bruchsal, wo er von Republikanern befreit wird (13. / 14. Mai 1850).

Agnes verbringt über ein halbes Jahr im Freiburger Turm und bekommt wie Amalie Struve von Freunden Kleidung und Bücher dorthin geschickt. Viele weitere zahlreiche Parallelen und Anklänge an die Badische Revolution, wie auch die Schweizer Orte Birsfelden und Rheinfelden, sind in Amalie Struves Erinnerungen aus den Badischen Freibeitskämpfen (Heftiges Feuer, 1998) nachzulesen.

Immer wieder tauchen die Gräber auf dem alten Wiehre-Friedhof in Freiburg auf an der Ecke Erwinstraße / Dreikönigstraße - heute Spielplatz - die Amalie Struve besucht hat. Hier müssen die Ostern 1848 in Günterstal und im Sternwald gefallenen Freischärler begraben worden sein.

Freiburger Frauen stifteten einen Gedenkstein mit der Inschrift „Hier ruhen die am 24. 4. 1848 bei Freiburg im Kampf für den Gedanken eines volksfreien Vaterlandes gefallenen Männer und Jünglinge“. Das Setzen des Steines wurde verboten; die Inschrift musste ausgemeißelt werden. Ohne Inschrift stand er dennoch „neben viel besuchten und beweinten Gräbern" lange Zeit auf dem Wiehremer Friedhof. Im Sommer 1849 wurden auf diesem Friedhof die Revolutionäre Maximilian Dortu aus Berlin, Gebhard Kromer aus Bombach (bei Kenzingen) und Friedrich Neff aus Rümmingen (bei Lörrach) standrechtlich erschossen und beerdigt. Heute ist nur noch das Mausoleum, das die Eltern Dortus errichten ließen und die Gedenkplakette für Neff und Kromer zu sehen.

Sowohl die Gräber von 1848 wie auch von 1849 wurden geschmückt. Sehr zum Ärger der Behörden, die am 24. September 1849 elf junge Mädchen und Frauen aus St. Georgen und Uffhausen deswegen verhaftet und einige von ihnen bis zu vierzehn Tagen in Haft hielten.

Zur Orthographie ist anzumerken, dass es zur Zeit Amalie Struves noch keine verbindliche Rechtschreibung gab. So lesen wir einmal von dem Ort Schliengen aber auch von Schlingen. Agnes Bruder heißt einmal Herrman und dann wieder Hermann usw.

MMM 